\title{
DIDAKTIKA GEOGRAFIJE VČERAJ, DANES IN JUTRI
}

Jurij Kunaver*

IZVLEČEK

UDK 911:371.3

Zavest o potrebi po strokovnem izobraževanju uciteljev geografije iz didaktike geografije v lastnem, slovenskem jeziku, je stara okrog sto let in ima bolj ali manj nepretrgano kontinuiteto do danes. Avtor ugotavlja, da se mora teoretǐna in aplikativna didaktika danes še bolj nasloniti na raziskovalno delo in na najboljక̌e tuje dosežke ter $s$ tem hitreje slediti trendom, ki so uspešni drugod.

\section{ABSTRACT}

UDC $911: 371.3$

\section{TEACHING GEOGRAPHY YESTERDAY, TODAY AND TOMMOROW}

The history of the professional education in teaching geography in Slovene language has an age of about one hundred ycars, without intermission. The author expresses the opinion that the nowadays theoretical and practical didactics of geography should be better linked with the research work and should also faster follow the results from abroad.

\section{UVOD}

Namen razprave je osvetliti sedanji trenutek v razvoju slovenske didaktike geografije v luxi preteklega razvoja in bodoxih nalog. Pri tem mislimo na didaktiko geografije kot znanstveno stroko, ki je obenem za celotno podrocje solske geografije. Zato pri tem ni mogoðe povsem loceno obravnavati razvoja, vscbine in organizacije univerzitetnega Stuciija didaktike geografije in njenega znanstvcno-raziskovalnega razvoja od razvoja in stanja geografije na vseh stopnjah solanja, pa tudi ne od nekaterih bistvenih vprasanj razvoja slovenske geografije kot znanosti v celoti.

Da bi dosegli pri razvoju geografske didaktike, in $\mathrm{v}$ zvczi s tem tudi pri pouku geografije, čim boljšc rezultate, je potrebno izpolniti več pogojev. Poglavitni so nasleđnji: 1. razvita zavest o zgodovinskem razvoju geografije kot celote in posebej didaktike, 2. kontinuiteta $v$ znanstvenem in pedagoskem razvoju stroke, 3. zveza med didaktieno teorijo in prakso, 4. skrb stroke kot celote za njen znanstveni in družbeni ugled, kar v tem kontekstu pomeni staino borbo za uvel javljanje geografije v soli, 5 . skrb za nadaljni razvoj teoretixne in praktične didaktike kot celote ter stalna in kritixna primerjava in oplajanje $\mathrm{z}$ dosežki drugih, 6 . skrb za kadre na podroxju didaktike geografije, tako za normalno reprodukcijo uxiteljev geografije oziroma zemljepisa in reprodukcijo didaktičnih strokovnjakov, 7. institucionaliziranje prizadevanj za razvoj in napredek didaktike geografije.

* Dr., izr.prof., Oddelck za geografijo, Filozofska fakulteta, Aškerčeva 12, 61000 Ljubljana, YU. 
Na tem mestu se ni mogoðe poglobiti \e v nekatera druga aktualna vprašanja didaktike geografije $\mathrm{v}$ Sirł̌m pomenu besede, zlasti $\mathrm{v}$ vpraßanja praktiæne ali aplikativne didaktike oziroma kratko šolskc geografije, kot so naprimer permanentno izobražcvanje uxiteljev, priprava uxnih pripomoxkov, opremljenost sol, odnosi med geografijo in drugimi కolskimi predmeti, organiziranost కolske geografije, ugled in veljava geografije $v$ družbi kot rezultat lastnih prizadevanj in tudi napak, itd. Vendar je celovito obravnavanje didaktike geografije zadostno zagotovilo, da ni mogoce povsem izpustiti nobenega od najpomembnejših podrocij Łolske geografije.

\section{TRADICIJA IN KONTINUITETA DIDAKTIKE GEOGRAFIJE}

Če primerjamo zgornje zahteve s stanjem v slovenski didaktiki geografije, pridemo do ugotovitev, ki niso povsem $\mathbf{v}$ skladu z njimi. $\mathrm{K}$ prvi tocki je mogoðe na splošno reči, da ina didaktika geografije pri nas razmeroma bogato in dolgo tradicijo, saj seže s prvo Orožnovo Metodiko v leto 1891; medtem ko smo prve slovenske zemljepisne učbenike in uxila dobili že sredi prejšnjega stoletja. Zgodovina pouka geografije v slovenšxini in didaktixncga razmixljanja o načnu izvajanja tega pouka ima torej vec kot stopetintridesetletno tradicijo, raðunajoð z letnico izdaje Kozlerjevega Kratkega slovenskega zemljepisa in pregleda. $\mathrm{K}$ temu pa lahko dodamo se podatek, da je geografija na naših tleh kot solski predmet zakoreninjena že veð kot 400 let (Schmidt, $1963,73)$.

Toda na vpraßanje ali se zavedamo vseh pomembnih ločnic tega razvoja ali encstavneje, ali sploh poznamo zgodovino lastne stroke, je odgovor negativen. Majhna podrobncst, $v$ nobeni dosedanji zgodovini slovenske gcografijc in కe manj diđaktike geografije ni omenjer.a Metodika zemijepisnega pouka v ljudski §oli.... Gabriela Majcna, ki je izsła v Gorici leta 1905. Današnji bralec lahko s presenecenjem ugotovi, da se nobeno podobno delo iz kasnejšega casa tako temeljito ne naslanja na takratno, ceprav vecinoma nemsko literaturo, kot prav to. Majenova Metodika je s 175 stranmi daię̌ najbolj obsežen priroxnik $\mathrm{v}$ primerjavi $\mathrm{z}$ drugimi metodikami, ki so izšle $\mathrm{v}$ tistem Casu.

Plodovi tako dolgega razvoja so torej vsekakor vidni, zlasti v obliki razmeroma bogate tcoretix̌ne in praktixne didaktiene literature, pa tudi $v$ łtevilu posameznikov, ki so se ukvarjali s pisanjem in izdajanjem didaktienega materiala. Ne nazadnje tudi s številom uxiteljev visokošlske didaktike. Slednje pomeni sicer le števiǐ̌no vrednost, toda iz tega se je razvila do neke mere tudi kvaliteta, saj se je krog posameznikov, ki so jih tudi aktivno zanimala vprasanja didaktike, moxno razširil. V vsakem obdobju v preteklosti, zlasti ko so se zaostrila kadrovska in strokovna vprasanja, se je našel kdo, ki ga je pritegnila tudi ta veja nase stroke in se ji je posvetil za krajši ali daljక̌ čas. 
Toda kljub క̌tevilennosti predavateljev didaktike v zadnjem obdobju, ali prav zato, je zaostalo poglobljeno znanstveno-raziskovalno delo. Morda tudi zato nimamo, razen Zgonikovega, nobenega sodobnejక̌ga ucbenika Metodike oziroma didaktike geografijc. Kljub temu lahko vsaj pritrdilno govorimo o kontinuiteti razvoja, ceprav so bile vmes tudi praznine.

\section{SKRB MATIČNE STROKE ZA RAZVOJ IN UGLED ŠOLSKE GEOGRAFIJE}

Glede cetrte zahteve se je potrebno spomniti bolj ali manj stalne aktivnosti in številnih intervencij stroke in njenih predstavnikov, tako iz univerze kot iz drustva in prakse, zaradi spreminjanja predmetnikov in oskodovanja fonda geografskih ur. Šolska geografija je doživela številne kvalitetne spremembc, zlasti v zadnjih desetletjih, pa vendar so §e vedno težave, kadar je treba prepricevati družbo o trajni in pomembni vlogi tega predmeta v sistemu vzgoje in izobraževanja. Nastopajo nove, konkurencne stroke, ki si iastijo nekdaj tradicionalne geografske vsebine.

Didaktika geografije se je morala boriti poleg tega tudi z poenostavljeno miselnost jo, ki se je nekateri se danes niso povsem znebili, da je to le tehnika cziroma obrt poucevanja oziroma prenašanja poenostavljenih znanstvenih spoznanj v šolo. Nehote je veljalo delo na tem področju za nekaj manj vredno in manj pomcmbno. Pociobno je razmišljal Jakob Medived ki ugotavlja, da so vmesni položaj didaktike geografije med geografsko znanostjo in obco didaktiko in nerazčsčeni pogleđii tako na predmet kot na vsebino in pocroxje raziskovanja didaktike gcografije rażıgi za "težave, ki so povzročile, da se didaktika geografije pri nas ni mogla razvijati kot samostojna znanost". Medved je takrat skußal skoraj žoľno obracunati z vsemi, ki niso imeli razumevanja za pos!anstvo didaktike geografije, saj jih je inenoval "czko usmerjene in družbeno nerazgledane geografe, ki jim že samo ime didaktika gcografije vzbuja alergijo, dvome in pomisleke. Za njih je bila sprejemljiva samo metodika geografije, toda ne kot znanstvena disciplina, temvec kot vesxina" $(1975,37)$.

Kot epizodo lahko zabeležimo v tej zvezi razpravljanje na oddelku za geografijo leta 1966 o negativnem staliscu posameznikov do potrebe po znanstveni usposobljenosti uXiteljev didaktike geografije, ‘eš "kakor je smiselno, da predavajo metodiko praktiki, tako je nesmiselno, da predavajo specialno metodiko fakultetni uxitelji, ki so usposobljeni za znanstveno delo". Medved se je takemu stalißcu uprl, kakor tudi trditvi, da "je metodika geografskega pouka v bistvu sistematixno podajanje izkußenj". Podobno kot Medved je razmisljal tudi prof. Ilešic, ki je zlasti zagovarjal poirebo po predavatelju diđaktike iz vrst fakultetnih učiteljev.

Didaktika geografija bo vedno potrebovala podporo in razumevanje najširšega kroga geografskih strokovnjakov, med njimi Se zlasti vrhunskih, pa tudi geograískih inకtitu- 
cij, ce bomo hoteli, da se skupaj z razvojem znanosti organsko razvija tudi \olska geografija kot najbolj množixna aplikacija njenih dosežkov. Šolska geografija je bila in bo zrcalo geografije kot celote. Še zlasti na tem podrox̌ju družbene sfere se ustvarjajo, oblikujejo, pa tudi spreminjajo predstave o naši stroki. To je podrocje vexne pozicijske borbe za boljši položaj v predmetniku in s tem za večji pomen in ugled predmeta. Iluzorno je prixakovati kakršnokoli popušcanje ali razumevanje $v$ tej borbi, kajti nekaterim vplivnim predstavnikom posameznih strok kot argument za diskriminacijo geografije zadošca že lastno mnenje. Zato je pred vso našo stroko staina naloga potrjevati se $s$ kvaliteto in s pravilnim razumevanjem njene družbene vloge (Verbix, 1987, 9-10).

\section{RAZVOJ TEORIJE IN PRAKSE, PRI NAS IN NA TUJEM}

Zveze med didakticno teorijo in prakso so pri nas bolj ali manj trajne in trdne, saj je komaj mogoce drugače. Vendar je naša didaktixna praksa precej moxnejša od teorije. Tudi zato veasih ne gre brez težav in odporov pri sprejemanju spoznanj geografske znanosti $v$ solstvu, najveckrat pa je to povezano s prevelikimi zamudami. Toda obilje člankov v Geografskem obzorniku z izrazito didaktično in se bolj metodično vsebino jasno kaže živo potrebo vseh aktivnih subjektov v geografskem solstvu po izražanju svojega mnenja in posredovanju svojih in tujih izkusenj.

Medved je leta 1975 ugotovil, da je v jugoslovanskem prostoru znanstveno raziskovalno delo iz didaktike geografije, razen redkih izjem, skoraj popolnoma neznano $(1975,38)$. In vendar hkrati trdi, da na področju metodike geografije po zaslugi posameznikov ne zaostajamo za evropskim nivojem, vendar tega konkretno ne utemeljuje.

Zanimiva je nedavna podobna ugotovitev iz didaktiæno neprimerno bolj razvitega britanskega okolja. Wiliiams $\mathrm{z}$ obžalovanjem pravi, da se angleški didaktiki veliko bolj ukvarjajo $\mathrm{z}$ uenimi naxtri in uxnimi oblikami kot pa s fundamentalnimi in teoreticnimi didaktiðnimi raziskavami, zaradi cesar je cutiti pomanjkanje znanstveno podprte literature (Williams, 1987, 92).

Prvi akademski naslovi iz didaktike geografije, ki so bili priłobljeni $\mathrm{z}$ raziskovalnim delom, od leta 1980 dalje (dektorat J. Malkoca), so ociten preobrat v razvoju. Ni dvoma, da je prav J. Medved s svojim delom odloxilno pripomogel k temu. S. Brinovec je 1981 obravnaval problematiko uporabe grafoskopa in prosojnic pri pouku geografije in je to tudi objavil v posebni publikaciji. Sledila je M. Kosakova s కtudijo o osvajanju in vrsti geografskih pojmov na prcdmetni stopnji osnovne šle, kmalu za njo pa V. Stepancix z razpravo o geografskih pojmih na razredni stopnji. 
$\mathrm{V}$ izdelavi sta dve novi magistrski nalogi iz področja didaktike obravnavanja lokaine geografije $v 3$. razredu srednje sole in iz problematike nivojske diferenciacije pri obvladovanju geografskih pojmov v 1. razredu srednje కole. Poleg tega so v teku se manjక̌e raziskave o povezavi med solo in okoljem pri pouku geografije .

Med raziskovalne poskuse lahko štejemo tudi nekatere evaluacije učbcnikov in učnih programov, ki so jih izvajali Zavod za solstvo in njegovi regionalni zavodi. Katedra za didaktiko oddelka za geografijo FF je izvedia tudi manjß̌e ankete in raziskave o vsebini in kvaliteti pouka geografije cziroma zemljepisa, naprimer o zastopanosti posameznih tematik $v$ uxbenikih in ucnih programih kot so naprimer kraske vsebine, varstvo okolja in naravne nesrece. $\mathrm{V}$ navedenih treh primerih smo lahko ugotovili pomanjkljivo obravnavanje teh za nas in za svet zelo pomembnih vsebin.

Med rezuitati, ki jih štejemo cieloma kot posledico vzpodbud katedre, deloma pa so izraz novega gledanja na pouk geografije, lahko omenimo tudi cksperimentalno delo nekaterih uxiteljev-praktikov. Posamezniki namureč preskušajo različne načine izvajanja ekskurzij, terenskega dela in naravoslovnih dni, zlasti na obmoxju Gorenjske, Postojne in obalnega kraškega obmoxja. V to so vkljuxene tudi nekatere jame na Postojnskem in Dimnice pri Divaxi. Na podlagi vnaprej izdelanega programa se učenci $v$ jami sistematixno spoznavajo s posebnostmi jamskih prostorov in njihovim nastankom. Pri tem aktivno opazujejo in beležijo.

Tako je $z$ intenzivnejsim raziskovanjem na podrocju cidaktike geografije izpolnjen še cin pomemibeñ pogoj za rijen skladen in celovit razvoj ier za njen ugled in enakopraven položaj v okviru geografije in pedagogike, pa cetudi bomo v naših razmerah š naprej v izdatni meri prisiljeni uporabljati tuja spcznanja. Prav na tem podroxju strokovnih stikov s tujino, ki so nezadostni, zaenkrat ni mogoče ugotoviti posebnih dosežkov. Redki so novejši slovenski avtorji didaktičnih prispevkov, ki so objavljali v tujini.

Razvoja didaktike geografije pri nas in v svetu ni mogoče povsem enakovredno primerjati tako zaradi razlixnega ekonomsko politixnega razvoja kot tudi zaradi razlixnih vzgojno- izobražcvalnih potreb posameznega naroda in nacije. Za naše razmere je značilno, da $v$ glavnem težko in s stalno veliko zamudo siedimo inovacijam na tem podroxju. Teoretično in $\mathrm{v}$ pedagcški praksi so najmoxneǰ̌ mnoge gospodarsko najrazvitejšc države $z$ močno konkurenco takơ na idejnem, strokovnem in proizvodnem podrocju. Razlika je zlasti v tem, da se je na zahodu mnogo prej uveljavil vpliv posameznih mislecev in teoretikov, ali skupinc ljudi, ki so s svojimi idejami in ustvarjanjen odloxilno vplivaii na uporabo teorije v praksi.

Zato imajo tudi posamezne sole npr. v Angliji, ali pa posamezne upravne enote, konkretno nemške zvezne dežele, za naše razmere veliko veð svobode pri sestavlja- 
nju predmetnikov, kjer geografijo (in tudi druge predmete) vanj vklju $x_{i j o}$ ali pa tudi ne. Tudi uxitelji geografije so v izbiri in podajanju snovi bistveno manj vezani kot pri nas. S tem je zaradi konkurencnosti vsekakor zagotovljena kvaliteta, toda gre lahko na racun obsega zastopa nosti posameznega predmeta. Teorctißna didaktika geografije najde za razlixne nove ideje hitreje in bolj plodna tla kot pa v naših razmerah. Od ene resnice ali enega recepta, ki smo jo vajeni pri nas, je to preskok v pluralizem idej in pogledov na isti predmet, na isto solsko snov. Toda tak popoln liberalizem si pri nas ne bi mogli privoščti zaradi nacionalnih interesov, Ceprav bi bilo prav, da postane z možnostjo izbiranja vsebin zaradi geografske pripadnosti šle tudi naక̌ uxitelj geografije bolj svoboden in stem bolj ustvarjalen.

\section{RAZVOJ SISTEMA IZOBRAŽEVANJA UČITELJEV GEOGRAFIJE V SLOVENIJI}

Šele v povojnem casu je didaktika geografije pod imenom Metodika pouka geografije prvið v naši zgodovini postala visokošolski predmet. To se je zgodilo v študijskem ictu 1957/58, prvi njen predavatelj pa jc postal Mavricij Zgonik, ki je predaval le cno leto. Pedagogiko so క̌tudenti geografije poslusali že od oktobra 1949 daije, ko je bil sprejet zađasni predmetnik. Mimogrede, $\mathrm{k}$ prostovoljnemu poslusanju tega predmeta so bili vabljeni కtudenti geografije že pred vojno.

Usoda didaktike je bila $v$ nadaljnem razvoju odvisna pogcsto od trenutnih okolisčin in interesov, zlasti pa od predavateljev, ki so se žal tudi zaradi prezgodnjih smurti věasih pogosto menjavaii. Do danes je na oddelku preaavalo didaktiko osem predavateljev (M. Zgonik, D. Radinja, D. Kompare, M. Žagar, J. Medved, M. Košak, S. Brinovec, J. Kunaver). Nekaj vec, deset, pa je bilo sprememo predmetnika. Didaktika je zaccla s 60 urani predavanj in prav toliko vajami. Od reforme Studijskega programa leta 1960 dalje je bila cidaktika razdeljena na 1. in na 2. stopnjo, z dodanimi 60 urami je imela skupno 180 ur.

Od leta 1964 so se razmere za didaktiko poslabSale zaradi ukinitve predavanj in vaj iz lega predmeta na 1. stopnji. Leta 1968 so studenti 4. letnika posiuxali v 4. letniku le 30 ur predavanj, 30 ur pa je ostalo za vaje. Ko je imel oddelek enega stainega predavatelja za didaktiko geografije v osnovni soli, drugega pa za srednjo క̌olo (J. Medved in M. Žagar), oba z izdelanim pogledom na predmet, so se razmere mox̌no izbolǰ̧̌le. Leta 1977 se je didaktika vrnila v 2. letnik s predavanji o didaktiki geografije v osnovni Soli s 120 urami, v 4. letniku pa so obravnavali didaktiko za srednje solske potrebe v 75 urah predavanj, 30 urah seminarja in 105 urah vaj. Po Medvedovi prezgodnji smrti sta ga nadomiestila dva zunanja sodelavca.

Sedanji predmetnik je stopil v veljavo leta 1985 po takratni reformi in je glede na 
prcteklost preccj okrnjen. Študenti se $\mathrm{v} 2$. letniku odloxijo za nepedagoßko ali pedagoško usmeritev. Po predavanjih iz splošnih pedagoško psiholoških predmetov poslu\ajo didaktiko geografije $v$ tretjem letniku 60 ur in enako $v$ cetrtem letniku. To je le $56 \%$ obsega didaktike iz leta 1977 . K temu bi sicer morali prišteti §e 30 ur za lokalno geografijo, ki jc bila uvedena $\mathrm{z}$ namenom aplikacije geografskih raziskovalnih metod v Solski geografiji na najnižji regionalni ravni. Na Filozofski fakulteti je bil hkrati na novo uveden tudi predmet Organizacija dejavnosti uðencev, $60 \mathrm{ur}$, ki je namenjen izobraževanju bodoxih uxiteijev o interesnih dejavnostih. Toda oba predmeta se zaenkrat ne predavata.

Snov didaktike geografije obdclamo $v$ treh semestrih, to je do zacetka letnega semestra $v 4$. letniku. $V$ petem semestru so predavanja o osnovnošolski didakiki geografije, v sedmem pa o srednjeక̌lski didaktiki geografije. Vmes so teoretǐne vaje, to je spoznavanje literature in uenih pripomoðkov, najveट pa je praktiðnih vaj ali nastopov, ki temu sledijo. Program predvideva tudi enotedensko ux̌no prakso $v$ osnovni కoli v 3. letniku in enotedensko učno prakso v srednji soli v 4 . letniku.

V tem obsegu je premalo casa za poglabljanje $\mathrm{v}$ nckatera temeljna vprašanja $\mathrm{s}$ pomoxjo literature in $\mathrm{s}$ tem za uvajanje $\mathrm{v}$ raziskovanje. Zato bi moralo biti didaktiki gcografije nujno vrnjeno seminarsko delo in $\mathrm{s}$ tem priložnost za samostojno razmišljanje in ustvarjalnost.

V Sloveniji se didaktika gcografije predava š na Oddelku za geografijo Pedagołke fakuitele v iviariboru, vendar closlej le na 1. stopn ji, s podobnim programom in organizacijo, kot jo je imela Pedagoska akademija v Ljubljani do leta 1985 , oziroma kot ga je nckoc imel ođđdelek za geografijo na 1. stopnji. Ta predmet je bil na pedagoskih akademijah ziasti glede obsega in organizacije dobro vpeljan in ni doživljal velikih sprememb. Ljubljanska pedagoška akademija je imcla po zaslugi T. Oblaka, enega od predavateljev didaktike, tudi zelo dobro opremljen didaktični kabinet. Priznati je treba, da so pedagoske akademije posredno ali neposredno vzpodbujale razvoj tega predmeta, ziasti na kadrovskem podroðju, ceprav je bila hkrati klima za znanstveno-raziskovalno dclo na teh ustanovah neugodna. Zaradi sprememb v fiziognomiji obeh slovenskih pedagoških akademij nckateri nekdanji predavatelji didaktike na predmetni stopnji đanes predavajo didaktiko Spoznavanja družbe. S tem se je pomen didaktike geografije na visokih pedagoški akademiji v L jubljani navidez zmanǰ̌al. V resnici pa gre za didaktično podroxje najzgodnejšega dojemanja in razvoja geografskega znanja pri ctroku, ki ima poseben pomen in je zato vredno našega enakovrednega zanimanja.

Končno se pomudimo še pri zadnjem pogoju za normalen razvoj stroke, to je pri njeni organiziranosti. $V$ Sloveniji je trenutno neposredno angažirano $z$ didaktiko geografije కest predavateljev in asistentov. Poleg njih lahko stejemo v krog nosilcev 
razlicnih aktivnosti na podroxju didaktike geografijc, kot so strokovni svetovalci, posamezni raziskovalci, redno nastopajoxi avtorji in pisci uðbenikov ter clankov se okrog dvanajst posameznikov. To కtevilo bi lahko se krepko povecali s posamezniki, ki se obcasno vkljuxijo $\mathrm{v}$ bolj poglobljeno delo na podroxju didaktike. To pa pomeni, da je $\mathrm{z}$ usodo didaktike geografije, ali v Siršem smislu s solsko geografijo, tesno povezano tolikšno stevilo ljudi, da nam ne more biti vseeno v kakšnih razmerah delajo in za kakšne cilje. To pa tuđi pomeni, da bi morala didaktika geografije imeti veliko boljšo strokovno in tehnixno-organizacijsko podporo za svoj razvoj, kot pa jo ima danes. Tudi na tem mestu se spominjamo J. Medveda, ki se je zavzemal za iste stvari, "za katedre za didaktiko geografije (ki so bile tisti Cas v Jugoslaviji కe redkost), za stalen raziskovalni kader za didaktixnogeografske raziskave in za združevanje vseh didaktikov visokošclske regije $\mathrm{v}$ didaktǐ̌nem središcu, ki bi vodilo in organiziralo tudi permanentno in podiplomsko izobražcvanje" $(1975,40)$.

$\mathrm{V}$ preteklosti je nał predmet imel takšno zaledje nekaj časa le v Inštitutu za geografijo Univerze, ko je bilo prek njega financirano in organizirano znanstveno-raziskovalno delo. Tako ta in tudi Geografski institut A. Mclika nista povsem pozabila na solsko gcografijo, če sodimo po aktivnosti v okviru gibanja Znanost mladini in pri izdajanju povsem pedagosko naravnanih geografskih publikacij, kar je vsekakor dober obet za prihodnost. Resnica tega trenutka je tudi, da sta Oddelck za geografijo FF in njena katedra za didaktiko geografije sicer dosegla nckaj uspehov, zlasti na podroxju permanentnega izobražcvanja, vendar je za marsikatere naloge kadrovsko preslabotna in slabo oprenljena. Posebno perex problem je denar za raziskovaino delo. Slaba povezanost geografskih institucij v Sloveniji zato zagotovo škoduje tudi didaktiki geografije.

$\mathrm{V}$ tem sestavku in poglavju poscbcj ne omenjamo aktivnosti komisije za geografsko vzgojo in izobrazbo Zveze geografskih drustev Slovenije in posameznih geografskih drustev posebcj, ker obravnavamo predvscm institucionalno organiziranost didaktike.

\section{NAMESTO ZAKLJUČKA RAZMIŠLJANJE O PRIHODNOSTI}

Po našem prepriðanju v bođođe ne bo šlo brez določene stopnje integriranosti v prizadevanjih in brez usklajenosti predstav o nalogah in ciljih didaktike geografije ter Solske geografijc, ki naj temeljijo na objektivnih znanstvenih dejstvih in najvisjih interesih stroke in družbe ‘e nočemo, da bo vsakdo ravnal po svojen osebnem trenutnem prepricanju in potreban, s čcmer bi v bisivu skodoval razvoju te stroke. Težave te vrste se najbolj jasno kažejo $v$ ponavl jajocih se pomanjkljivostih geografskih కolskih učbenikov, ki pa naj bi bili nase zrcalo $v$ javnosti. 
Obeti tesnejsih gospodarskih in morda tudi politixnih odnosov v Evropi so nujno povezani tudi z zbliževanjem med narodi in kulturami, tudi pri vzgoji in izobraževanju. V mislih nimamo nekega vzgojno-izobraževalnega poenotenja, unificiranja, na sprotno, predvidevamo lahko le mnogo večjo odprtost za tuje dosežke in boljše rešitve od nasih. To in pa vex lastnih raziskovalnih rezultatov je lahko garancija, da didaktika geografije ne bo capljala na mestu in ponavljala samo starih resnic. Izobraževanju bodočih geografov-uðiteljev in permanentnemu izobraževanju bo treba posvetiti క̌e vex pozornosti, kakor tudi splošni modernizaciji uð̌nih načrtov ter smotrov geografskega pouka. Izziv $s$ satelitsko televizijo in $\mathrm{z}$ najmodernejš televizijsko snemalno tehniko, ki bo zdaj zdaj dostopna skoraj vsakomur, mora sprejeti tudi didaktika geografije. Toda napažno bi bilo zanasati se samo na tehniko in opremo. Posodabljati je treba tudi vscbino in oblike geografskega pouka. Čaka nas Se veliko dela predno bomo $v$ našc šle uvedli nekatere nove oblike in vsebine geografskega pouka, ki so drugod v praksi že precej casa. Trenutno pa imamo కe vedno težave, kako navaditi prav vsakcga uxitclja na terensko delo. 


\section{LITERATURA IN VIRI:}

Haubrich, H., 1987. Some recent activities for improving geographical education in the federal Republic of Germany. International trends in geographical education. Ed. H. Haubrich. IGU, Commission on Geographical Education, Freiburg.

Košak, M., 1987. Geographical education in Yugoslavia. International trends in geographical education. Ed. H. Haubrich. IGU, Commission on Geographical Education, Freiburg.

Kunaver, J., 1987. Kras v slovenskih geografskih uxbenikih. Geografski obzornik 34,st. 2, L jubljana.

Kunaver, J., 1989. Varstvo okolja in pouk geografije. Slovenija 88-okolje in razvoj. SAZU, Svet za proucevanje in varstvo okolja. Ljubljana.

Medved, J.,1975. Sodobna koncepcija didaktike in metodike geografije, Geografski obzornik 22, st.3-4, L jub! jana.

Schmidt, V., 1963. Zgodovina Solstva in pedagogike na Slovenskem I. DZS. Ljubljana. Študijski naxrti za geografijo. Oddelek za geografijo FF, Ljubljana.

Verbic, M., 1987. Geografija v našem vzgojnoizobraževalnem sistemu. Geografski obzornik 34, št. 2, L jubljana.

Williams, M., 1987. Theory and Practise in Secondary School Geography in England and Wales. International trends in geographical education. Ed. H. Haubrich. IGU, Commission on Geographical Education, Frciburg.

Zgonik, M., 1960. Metodika geografskega pouka. DZS. Ljubljana. 


\section{TEACHING GEOGRAPHY YESTERDAY, TODAY AND TOMMOROW}

The tradition of teaching geography has been pretty long in Slovenia; it started 400 years ago. The first Slovene textbook on geography originates in the middle of the 19 th century and the birth year of the first textbook on didactics of geography is 1891. After the World War I and after establishing the University of Ljubljana together with the Department of the geography there was the first opportunity was given to introduce a modern curricullum in elementary and in secondary schools. And only after the World War II, as late as 1957 , the students of geography could for the first time attend lectures on didactics of geography.

The purpose of the articie is to give a survey of the development and to present the problems of theory and practice of teaching geography in Slovenia. Till now, the subject "Teaching Gcography" has been organized by the Department of Geography at the University of L jubljana mostly in two parts: (1) a one year programme for the theory and practice of teacining in elementary schools, and (2) a one year programme for teaching in secondary schools.

The whole programme has been changed a lot during the course years: first of all it extent, which used to be 120 hours of lectures and practical work in average, and 330 hours as maximum. Also the lecturers have of ten been changed, which has not contributed to writing new study items.

There is a common lack of the scientific work on didactics of geography in Slovenia, which is due to the fact that only a few people are dirrectly connected with the lecturing didactics, and with geographical institutions. On the other hand, there are numcrous geographers, mostly from different schoois, who are interested in common questions on school curriculum and teaching geography, who have published many articles in Geografski obzornik. But nearly always some difficuities occure when something new is to be introduced into the syllabus, especially if it originates from a foreign country. Gcographers who teach in schools, make use of foreign literature very rarely, due to language obstacles and unfavorable economic situation in our country.

Therefore the Department of Geography and other geographical and pedagogical institutions have an important role in transferring universal geographical knowledge to teachers. This is also important, if we have in mind the future economic and political integrations in Europe and better communication between the curopean and world nations. 
Among many tasks which are to be realised in techniques of teaching geography we could mention that the Slovene teachers are just now acquiring the knowledge of better realisation of field work in schools, they are slowly introducing the use of computers and television. They have also become a little bit freer in up-dating the syllabus, as to the problems of ecology, natural disasters and world conflict areas. 